\title{
CORRESPONDENCE
}

\section{CHILD PSYCHIATRISTS}

DeAr Sir,

I should be grateful if through your columns I might draw attention to the DHSS Circular HC(79)7, entitled 'Psychiatrists Employed in the Community Child and Adolescent P'sychiatric Services'.

This circular explains in detail how those psychiatrists who prior to 1974 were employed by the local authorities and had not been graded as Consultant within the NHS and since 1974 have been transferred to the NHS may decide whether they wish

\section{SPECIALIST TRAINING IN CHILD PSYCHIATRY}

DeAr Sir,

Dr Lumsden Walker's letter in the February 1979 Bulletin (p 31) concerning specialist training in child psychiatry could, on cursory reading, suggest an apparent contradiction between the recommendation that "all trainees in General Psychiatry should have some exposure to Child Psychiatry at Registrar level" and discouraging "the establishment of further Child Psychiatric training posts at Registrar level".

Resolving this may hinge on whether the term "training posts" is held to refer to General Psychiatric or advanced specialist training. APIT supports the view that practical experience in Child Psychiatry for a six month placement (or equivalent) should form an essential part of the three year SHO/Registrar General Psychiatric training. This would normally mean the establishment of such posts as part of every rotational training scheme, whereas many at present do not have them, or if in existence they are only available to trainees who intend to specialise later in Child Psychiatry. On the other hand there are several such posts existing outside any rotational scheme, and to apply for Consultant status within the Health Service.

It contains application forms for such a review, together with details of addresses from which may be obtained further information regarding implications for conditions of service, etc.

\section{W. LUMSDEN WALKER}

Chairman, Child and Adolescent Psychiatry Section Bristol Royal Hospital for Sick Children, St Michael's Hill, Bristol BS2 8BJ.

aspirant child psychiatrists in them may well find their careers blocked by difficulties with the MCRPsych examination, as Dr Lumsden Walker suggests.

It would seem logical that these posts should be incorporated into existing rotational schemes, thereby alleviating both the shortage within rotations and the risks of professional isolation outside them, while perhaps retaining flexibility allowing, in specific instances, non-psychiatrists (such as progressive GPs or paediatricians) to have access to them.

APIT therefore supports the establishment of further SHO/Registrar posts in Child Psychiatry within the existing rotations, provided that these are limited to six months. This should improve the quality of "general professional training in preparation for the MRCPsych examination" and adequately prepare trainees for advanced specialist training which usually begins at Senior Registrar level.

Francis Crfi.j for APIT Executive Committee.

Department of Psychiatry,

The London Hospital,

Whitechapel, London EI IBB.

\section{NOTICE TO CONTRIBUTORS}

Articles submitted for consideration for publication in the Bulletin should be received at least two months prior to the date of publication. The length should not exceed 2,000 words, and two copies of the manuscript are required. 